\title{
PREVENÇÃO DA COVID-19 NA POPULAÇÃO IDOSA INDÍGENA
}

\section{Cássia Rozária da Silva Souza' \\ ORCID: 0000-0001-9790-3713 \\ Deyvylan Araujo Reis" \\ ORCID: 0000-0001-9314-3745}

Fernanda Farias de Castro"'I

ORCID: 0000-0003-1970-5169

Lígia Carreiraiv

ORCID: 0000-0003-3891-4222

Vanusa do Nascimento ${ }^{v}$ ORCID: 0000-0003-4141-2784
Autor Correspondente: Cássia Rozária da Silva Souza E-mail:crsouza@uea.edu.br

Como citar

Souza CRS, Reis DA, Castro FF, Carreira L, Nascimento V. Prevenção da covid-19 na população idosa indígena. In: Santana RF. Enfermagem gerontologica no cuidado do idoso em tempos da COVID 19. 2.ed.rev. Brasilia, DF: Editora ABEn; 2020. p.11-16.

(Serie Enfermagem e Pandemias, 1). https://doi.org/10.51234/aben.20.e01.c02

\section{INTRODUÇÃO}

A infecção humana causada pelo novo Coronavírus (SARS-Cov-2) produz a doença classificada como COVID-19. Esta doença representa uma emergência de Saúde Pública de importância mundial, com alto grau de mortalidade entre os idosos, pela progressão mais rápida da infecção viral nessa população ${ }^{(1)}$.

No mundo, o novo Coronavírus já atingiu cerca de 2.423.470 pessoas confirmadas com a COVID-19 e 166.041 óbitos. Atualmente, o país com o maior número de caso é o Estados Unidos. O Brasil ocupa a $11^{\circ}$ posição em número de casos com 40.581 brasileiros com COVID-19 e 2.845 mortes, sendo 1.492 de óbitos na população idosa (2).

A população idosa pertence aos grupos de risco para as condições mais graves e mortalidade da COVID-19, ocasionada, muitas vezes, pela alteração fisiológica do envelhecimento e somada com as comorbidades crônicas. Os estudos em Wuhan, capital da província de Hubei, na China, evidenciaram que as pessoas com 70 anos ou mais tiveram dias médios mais curtos ( 11,5 dias) desde o primeiro sintoma até a morte do que aqueles com idades abaixo de 70 anos (20 dias), demonstrando que os idosos podem ter uma progressão mais rápida da doença do que os mais jovens ${ }^{(1)}$.

Nessa perspectiva, os idosos precisam de maior atenção e proteção para não contrair o vírus, sendo necessárias medidas de adoção de higiene rigorosas, isolamento social, distanciamento, além de evitar contato próximo de pessoas doentes, higienizar as mãos com maior frequência e, não abraçar nem beijar.

No entanto, preocupa-se nesse texto com avanço da pandemia nos povos indígenas, dada sua vulnerabilidade social, os aspectos culturais e o contato interétnico. Essa população, no Brasil, é representada por 896.917 pessoas, ocupando mais de 4.200 terras indígenas, localizadas em 432 municípios de 24 estados ${ }^{(3)}$. 
Em outro aspecto, essa preocupação com a população indígena se torna real, pois a Secretaria Especial de Saúde Indígena (SESAI), já constatou no seu boletim epidemiológico, 31 casos confirmados e três mortes de indígena no país ${ }^{(4)}$. Importa registrar ainda que, no atual cenário, não há vacinas ou medicamentos com evidência científica para o seu tratamento definitivo, e o tratamento é voltado para suporte e controle de sintomas.

O estudo se justifica no sentido de proporcionar os cuidados de Enfermagem ao idoso indígena na prevenção da pandemia do novo coronavírus no Brasil, além de contribuir na assistência prestada pelo Enfermeiro nesse grupo etário de risco. Diante das considerações apresentadas e, tendo em vista a necessidade de novas investigações científicas com foco na temática em questão.

\section{OBJETIVO}

Realizar uma reflexão acerca da prevenção do COVID-19 e o papel do Enfermeiro ao idoso indígena.

\section{MÉTODO}

Trata-se de um estudo descritivo, de reflexão teórica, desenvolvido com aporte na literatura, análise e apresentação dos resultados. A reflexão proposta foi embasada na literatura nacional e internacional. A apresentação foram organizadas em categorias, a saber: acesso à saúde indígena, cenário da saúde indígena e a COVID-19 e o papel do Enfermeiro diante da infecção da COVID-19 em idosos indígenas.

\section{ACESSO À SAÚDE INDÍGENA}

Diversas barreiras de acesso aos povos indígenas têm sido descritas como limitadoras da atenção à saúde desses povos tradicionais em distintas regiões do mundo ${ }^{(5)}$. Entre os principais obstáculos apontam-se barreiras organizacionais, geográficas e culturais, incluindo limitações relativas à ausência ou incipiência de intérpretes culturais que permitam maior comunicação das etnias com os serviços de saúde ${ }^{(6)}$.

Dentre os países da América Latina, o Brasil é um dos que possui a menor concentração de povos indígenas, abaixo de $5 \%$ em relação aos demais países. Proporcional ao dimensionamento geográfico, os povos indígenas do Brasil se apresentam com uma diferenciação expressiva no que consiste em cultura, língua, condições econômicas e sociais, costumes e territorialidade, marcadas em seu modo de viver, na alimentação e na socialização com os demais( ${ }^{(5)}$. Esse grupo, distribuído em 505 terras indígenas, ocupa 12,5\% do território nacional. Apesar do contingente populacional não tão expressivo, em relação ao total da população brasileira, esses povos apresentam imensa sociodiversidade, incluindo 305 grupos étnicos falantes de 274 idiomas ${ }^{(7)}$.

Como em muitos países, o serviço de saúde que é apresentado ao povo indígena ainda tem fragilidades marcantes e antigas, permeada por leis enrijecidas e que servem de limitação para a melhoria e qualificação da rede de atenção à saúde em todo o território brasileiro. Cabe destacar que, desde 1999, houve importantes mudanças no sistema de saúde voltado para os povos autóctones, com a responsabilidade de prestar atendimento a toda população aldeada em terras indígenas, com a implantação dos Distritos Sanitários Especiais Indígenas (DSEls), de norte a sul do país. Estes se caracterizam como uma rede interconectada de serviços de saúde, capaz de oferecer cuidados de atenção primária à saúde, adequados às necessidades sanitárias da maioria da população, que são considerados ambientes étnicos e culturais dinâmicos e têm o dever de prestar atenção básica aos indígenas aldeados, sem guardar relação direta com os limites dos estados e municípios onde estão localizadas as terras indígenas ${ }^{(6)}$.

Segundo Andrade e Terra ${ }^{(8)}$, a Política Nacional de Atenção à Saúde dos Povos Indígenas foi integrada na Política Nacional de Saúde em 2002, por meio da Portaria Federal do Ministério da Saúde n² 254, de 31 de janeiro de 2002. A proposta dessa política: 
"... é garantir aos povos indígenas o acesso à atenção integral à saúde, de acordo com os princípios e diretrizes do Sistema Único de Saúde, contemplando a diversidade social, cultural, geográfica, histórica e política de modo a favorecer a superação dos fatores que tornam essa população mais vulnerável aos agravos à saúde de maior magnitude e transcendência entre os brasileiros, reconhecendo a eficácia de sua medicina e o direito desses povos à sua cultura".

Historicamente, os povos indígenas vêm enfrentando cenários não muito favoráveis a sua própria existência, transformação e interação com o restante dos brasileiros, em detrimento de embates territoriais, aceitação da cultura e costumes, modo de viver e pelo desejo próprio de como eles escolhem interagir com essas pessoas que agora configuram dentro de suas realidades, refletindo seriamente na saúde e nos serviços oferecidos a eles no país.

Alguns autores ${ }^{(9)}$, no estudo denominado "A Política de Atenção à Saúde Indígena no Brasil breve recuperação histórica sobre a política de assistência à saúde nas comunidades indígenas" destacam que os princípios para a constituição e consolidação desta política de atenção diferenciada à saúde dos povos indígenas devem sempre estar embasados nos seguintes marcos referenciais: (1) Reciprocidade: resulta da necessidade de buscar uma coexistência equitativa entre as comunidades indígenas e os agentes de intervenção na saúde; (2) Eficácia simbólica: requer uma compreensão ampliada do universo simbólico indígena como condição indispensável para a atuação em saúde; (3) Integralidade: visa a integração de uma forma global e criativa da problemática indígena, e dos fatores que atuam sobre os determinantes históricos, sociais, culturais e ambientais da saúde; (4) Autonomia: busca a construção de mecanismos de autogestão e da gestão participativa nos programas de saúde implementados nas comunidades, dentro da perspectiva maior da autonomia dos povos indígenas.

Entretanto, implementar, de modo eficiente, gestão e atenção à saúde dos povos indígenas, baseados nestes marcos referenciais está longe de ser uma tarefa fácil. Assim, há muitas décadas os Povos Indígenas do Brasil com o suporte de seus aliados e parceiros vêm discutindo e lutando por uma gestão mais eficiente na saúde e cuidado de cada comunidade ${ }^{(9)}$. Segundo Altini et al.:

"Considerados "entraves ao desenvolvimento", o destino dos povos indígenas sempre foi traçado nos termos do dominador. O direito de existência futura, com distintos modos de pensar, de organizar-se e relacionar-se com o mundo, sempre lhes foi negado. A falta de políticas públicas relativas à educação e saúde, e a demarcação de territórios insuficientes para o modo de vida tradicional, são respostas históricas com premissas integracionistas. Não é à toa que o atendimento à saúde se restringe a medidas paliativas e emergenciais" (9).

Na realidade, a chamada "política indigenista" tem sido caracterizada, ao longo da história do Brasil, pela forte interveniência do poder público, ainda que consorciado a entidades religiosas e civis. Esta política até pouco tempo tinha a clara perspectiva de promover a assimilação dos povos indígenas à sociedade brasileira.

\section{CENÁRIO DA SAÚDE INDÍGENA E A COVID 19}

O mundo inteiro está enfrentando os desafios do novo Coronavírus. Nas 305 etnias no Brasil e com 274 línguas, com cerca de 820 mil mulheres, homens e crianças indígenas, as questões mais sérias são a prevenção, contaminação e o acesso à saúde que precisam ser trabalhadas como estratégias de medidas de contenção da disseminação da COVID-19.

Há pelo menos 500 mil indígenas que vivem em áreas rurais, desse modo municípios dentro do mesmo estado, os atendimentos de saúde são diferenciados, dificultando a assistência prestada aos povos indígenas brasileiros. No dia $1^{\circ}$ de abril, foi confirmado o primeiro caso de contaminação indígena no Brasil: uma mulher indígena no interior do Amazonas, que atua na área da saúde.

A população indígena tem um passado histórico de doenças infectocontagiosas, que ressurge com a COVID-19, em que existe um grande risco de elevados índices de mortalidade nesse grupo. Assim, para evitar 
que isso aconteça são necessárias medidas de prevenção urgentes, implicando no comportamento de hábitos dentro de um contexto cultural, além do isolamento e o distanciamento social.

A fragilidade do sistema de saúde em atender a demanda de casos de COVID-19 ou de qualquer outra doença, as dificuldades de acesso geográfico entre as comunidades e os locais de assistência e as peculiaridades de cada aldeia e/ou etnia, só reforçam a necessidade de se instalar o isolamento social e os cuidados de prevenção contra a COVID-19 ${ }^{(10)}$.

\section{O PAPEL DO ENFERMEIRO DIANTE DA PREVENÇÃO DE INFECÇÃO DA COVID-19 EM IDOSOS INDÍGENAS}

Sabe-se que os idosos indígenas são mais vulneráveis à epidemia da COVID-19 em função de condições sociais, econômicas, culturais e de saúde. Os sistemas de saúde estruturados aos indígenas, em 2010, passam a ser por meio da Secretaria de Atenção Especial à Saúde Indígena (SESAl), para oferecer garantias de assistência integral, bem como o fortalecimento da atenção primária à saúde desse grupo populacional, respeitando os saberes tradicionais ${ }^{(7)}$. Nesse sentido, para o cuidado ao idoso, deve, ser beneficiária de ações de promoção à saúde e prevenção contínuas ${ }^{(11)}$.

Exige-se, desse modo, uma forte Atenção Primária à Saúde em território indígena, capaz de coordenar, a partir de critérios epidemiológicos, geográficos e etnográficos, o percurso terapêutico do idoso indígena, além de facilitar a prestação de serviços, ações de saúde em local e tempo oportunos ${ }^{(11)}$. Entretanto, encontra-se nesse cenário, um quadro de precariedade e dificuldades de acesso aos serviços de saúde e, principalmente, do atendimento em saúde ao idoso indígena.

O papel do Enfermeiro na sua atuação nos serviços do Subsistema de Atenção à Saúde Indígena e dos Distritos Sanitários Especiais de Saúde Indígena (DSEls), ressalta a necessidade de fornecer uma atenção diferenciada que garanta aos idosos indígenas, concomitantemente, o acesso universal aos serviços de saúde, assim como o respeito e a valorização da medicina tradicional ${ }^{(12)}$. Neste contexto, algumas condutas realizadas por Enfermeiros são de extrema relevância para a prevenção da infecção do Novo Coronavírus aos idosos indígenas. As ações que se destacam na prática assistencial são:

- Organização de um fluxo de atendimento para a triagem e reconhecimento precoce de casos suspeitos da COVID-19, nos DSEls;

- Orientação da equipe do DSEI para atuação na identificação, notificação e no manejo oportuno de casos suspeitos de infecção humana por SARS-CoV-2 de modo a mitigar a transmissão do vírus na terra indígena, com ações sempre baseadas nos protocolos de manejo clínico às pessoas com COVID-19, do Ministério da Saúde e da OMS;

- Realizar a interlocução dos profissionais de saúde com as lideranças da Terra Indígena (Cacique) para obter o apoio às orientações necessárias aos idosos indígenas na prevenção da infecção da COVID-19, tais como as restrições do contato entre os indígenas e os cuidados de higiene das mãos, corporal e do ambiente;

- Explicar à população idosa indígena a gravidade da COVID-19, suas formas de transmissão e prevenção da doença, utilizando como apoio o intermédio dos Agentes de Saúde Indígena (AIS), profissionais imprescindíveis na execução e na articulação dos cuidados aos idosos indígenas, uma vez que fazem parte da tradição cultural e conhecem a língua, costumes, valores, mitos e ritos desta população assistida;

- Fortalecimento de ações emergenciais de proteção à saúde dos idosos indígenas, com auxílio dos AIS e das redes de apoio em território indígena;

- Realizar a vacina Influenza em todos idosos indígenas no DSEl;

- Notificar a SESAI os casos suspeitos no DSEl para acompanhamento, isolamento e demais providências para o controle da transmissão comunitária e o cuidado ao indígena idoso. 
Por fim, destaca-se que o enfermeiro deve atuar na linha de frente junto ao Subsistema de Atenção à Saúde Indígena no âmbito do Sistema Único de Saúde (SASI-SUS), na prevenção e no cuidado aos idosos indígenas. As ações do Enfermeiro diante da prevenção, identificação e isolamento dos casos suspeitos da COVID-19 em territórios indígenas, deve considerar as diferenças culturais de cada povo e atuar de modo eficiente e eficaz no enfrentamento do processo epidêmico.

\section{Limitações}

As reflexões realizadas foram oriundas de documentos e estudos disponíveis na literatura e na mídia impressa governamental, o que significa se tratar de muitas matérias que não se referem especificamente à disseminação da infecção da COVID-19 em população indígena brasileira.

Outra limitação é que o Brasil possui 305 diferentes etnias indígenas, sendo registradas 274 línguas, presentes em 567 terras indígenas, nas cinco regiões do país. Esta diversidade de povos e cultura indígena exige aprofundamentos analíticos que levem em consideração dados censitários, as especificidades de cada etnia e seus contextos geográficos específicos, como é o caso das terras indígenas, o que sinaliza a importância de investigações e análises futuras.

\section{Contribuições para enfermagem}

O estudo contribui para refletir acerca da prevenção da COVID-19, e a importante atuação do enfermeiro, no subsistema da Atenção à Saúde Indígena (DSEl), para implementar ações de proteção ao idoso indígena de infecções pelo novo coronavírus. Sabe-se das dificuldades de diversas ordens, em níveis de gerência, recursos humanos e articulações de ações na rede de Atenção à Saúde do SUS, como, controle social ineficiente e entraves na comunicação entre as instituições governamentais, os representantes indígenas e as suas comunidades, gerando dificuldade de dados demográficos e epidemiológicos. Entretanto, é fundamental que haja investimentos na disseminação de informações sobre o cenário epidemiológico da COVID-19 entre os povos indígenas no país, considerando a sociodiversidade dos mesmos e a presença expressiva dos profissionais de enfermagem entre essa população.

\section{CONSIDERAÇÕES FINAIS}

Os desafios para garantir a proteção contra a infecção do novo Coronavírus dos idosos indígenas em seus territórios são imensos, considerando seus modos de vida e organização social. Uma estratégia que pode ser usada na prevenção ao novo Coronavírus é controlar o fluxo de pessoas em territórios indígenas.

O direito de receber informações, a qualidade da comunicação sobre os casos e o cenário da COVID-19 com os indígenas não podem ser usados como fatores vulneráveis para o atendimento na rede de saúde que os assiste. Os planos de contingenciamento não são claros, ou, nem ha definição sobre essas ações e seu desenvolvimento.

Nesse sentido, os enfermeiros, em conjunto com os demais integrantes da equipe de saúde que trabalham nos Distritos Sanitários Especiais Indígenas (DSEls) são os agentes estratégicos para atuar em conjunto com as lideranças indígenas no enfrentamento dessa problemática.

\section{AGRADECIMENTO}

Ao Departamento Científico de Enfermagem Gerontológica da ABEn Nacional.

\section{REFERÊNCIAS}

1. Wang W, Tang J, Wei F. Updated understanding of the outbreak of 2019 novel coronavirus (2019-nCoV) in Wuhan, China. J Med Virol 2020; 92:441-447. doi:10.1002/jmv.25689. 
2. Brasil. Ministério da Saúde. Centro de Operações de Emergência em Saúde Pública-Doença pelo Coronavírus 2019. Boletim COE e COVID, 20 de abril de 2020. Disponível em:https://portalarquivos.saude.gov.br/images/pdf/2020/April/21/BE13-Boletim-doCOE.pdf.

3. Brasil. Ministério do Planejamento, Orçamento e Gestão (BR), Instituto Brasileiro de Geografia e Estatística. Censo demográfico 2010: características gerais dos indígenas: resultados do universo. Rio de Janeiro: IBGE, 2010.

4. Brasil. Ministério da Saúde. Secretária Especial de Saúde Indígena. Boletim Epidemiológico SESAl, 21 de abril de 2020. Disponível em: http://www.saudeindigena. net.br/ coronavirus/pdf/21_04_2020_BoletimepidCOVIDSESAI.pdf.

5. Chagas CA, Castro TG, Leite MS, Viana MACBM, Beinner MA et al. Prevalência estimada e fatores associados à hipertensão arterial em indígenas adultos Krenak do Estado de Minas Gerais, Brasil. Cad. Saúde Pública, 2020; 36(1):e00206818. doi: https://doi. org/10.1590/0102-311x00206818.

6. Gomes SC, Esperidião MA. Acesso dos usuários indígenas aos serviços de saúde de Cuiabá, Mato Grosso, Brasil. Cad. Saúde Pública, 2017; 33(5):e00132215.doi: https://doi.org/10.1590/0102-311x00132215.

7. Mendes AM, Leite MS, Langdon EJ, Grisotti M. O desafio da atenção primária na saúde indígena no Brasil. Rev Panam Salud Publica. 2018;42:e184.doi: https://doi.org/10.26633/ RPSP.2018.184.

8. Andrade GASCR, Terra MF. Assistência de enfermagem à população indígena: um estudo bibliográfico. ArqMedHospFacCiencMed Santa Casa São Paulo. 2018;63(2):100-4.doi: https://doi.org/10.26432/1809-3019.2018.63.2.100.

9. Altini E, Rodrigues G, Padilha L, Moraes PD, Liebgott RA. A (Orgs.) Política de Atenção à Saúde Indígena no Brasil: breve recuperação histórica sobre a política de assistência à saúde nas comunidades indígenas. Conselho Indigenista Missionário - CIMI, 2013. Disponível em: <https://www.cimi.org.br/>. Acessado em: abril 2020.

10. COVID-19: prevenção e acesso a saúde são questões urgentes para mulheres indígenas. Internet (15 abril 2020). Disponível em:https://nacoesunidas.org/covid-19-prevencao-e-acesso-a-saude-sao-questoes-urgentes-para-mulheres-indigenas/. Acesso: 18 de abr de 2020.

11. Tarrant C, Windridge K, Baker R, Freeman G, Boulton M. 'Falling through gaps': primary care patients' accounts of breakdowns in experienced continuity of care. Family practice, 2015; 32(1):82-87. doi: 10.1093 / fampra / cmu077.

12. Rissardo LK, Carreira L. Organização do serviço de saúde e cuidado ao idoso indígena: sinergias e singularidades do contexto profissional. Rev. Esc. Enferm. USP [Internet]. 2014; 48(1):72-79.doi:10.1590/S0080-623420140000100009. 